\title{
USING MONTE CARLO SIMULATION TO MITIGATE THE RISK OF PROJECT COST OVERRUNS
}

\author{
ZAKIA BOUAYED \\ Defence Research and Development Canada - Centre for Operations Research and Analysis.
}

\begin{abstract}
Cost overruns are common on government and commercial projects. This paper proposes a cost risk estimating method that provides more accurate estimates of total project cost and answers the following important questions: (1) What is the most likely cost? (2) How likely is the baseline cost estimate to be overrun? (3) How much contingency is required on the project to guarantee that the total project cost is not to be exceeded, with a certain confidence level? The proposed method is based on the Monte Carlo simulation. It helps gain better information than traditional cost estimating methods, mainly because it recognizes that project costs are uncertain. A fictitious case study was developed to provide a structured way to provide the contingency value of a project in order to avoid cost overruns. Data were collected on low, most likely and high possible costs and the @ Risk software from the Palisade Corporation was used to run the Monte Carlo simulations. Using a simplified cost case study, this paper demonstrates how Monte Carlo simulation can assist project managers in estimating the contingency to be allocated to their project, and contribute to fostering and bolstering the credibility of risk analysis results.

Keywords: contingency, cost estimating, cost overruns, monte carlo simulation, risk analysis.
\end{abstract}

\section{INTRODUCTION}

Cost overruns have been shown to occur in a significant number of Defence projects. Auger [1] noted that despite the introduction of defence procurement reforms in recent years, Canada, and its allies continue to face cost overruns and delays with the delivery of major weapon systems and military equipment. The problem is not unique to the Canadian Defence sector. It affects all kinds of projects in different sectors of the economy, in Canada and worldwide. New research by Flyvbjerg [2] found that cost overruns occurred on nine out of ten megaprojects and concluded that 'overruns of up to 50 percent in real terms are common, over 50 percent not uncommon'. Notorious examples of project cost overruns from all over the World were reported in Flyvbjerg's research work. Among them, one can find the disastrous project for the construction of the Montreal Summer Olympics in Canada, which ended-up costing 13 times its original price estimate.

Cost overruns are problematic. They don't necessarily lead to project failure, but they do create budgeting problems and take money from other priority projects. In the public sector, cost overruns also translate into a loss of public confidence in the way the government manages taxpayers' money.

What causes such cost overruns? In the Defence world, Younossi et al. [3] identified the complexity of technology, the scale of the program and the over-optimism of program managers who overlook certain problems as the main reasons for cost overruns. Other factors 
found on the internet as to why project cost overruns may occur include: design errors; frequent changes in the project scope; escalation of costs associated with a project (labour, materials, equipment, administration, etc.) due to unforeseen events; unexpected project delays that automatically translate into more time and money; and poor management.

While these causes are valid in some cases, the main cause for cost overruns, as Flybjvberg et al. [4] indicates is cost underestimation. 'Projects promotors routinely ignore, hide, or otherwise leave out project costs and risks in order to make total costs appear low'. In other words, artificially low costs are presented to gain initial project approval, and then, once projects get underway, costs are revised upward. The cure for this is of course transparency and accountability, but also better cost estimating methods to account for risks and uncertainties over the life cycle of a project.

This paper proposes a simple and sound cost risk estimating method to apply to any type of project, in order to mitigate the risk of cost overruns. It should be noted that better cost estimates would not necessarily save any money; however, they would provide decision makers with a better basis for deciding whether to pursue a given program, thus avoiding potential project cost overruns.

\section{CONTINGENCY DEFINITION}

The objective of contingency allocation is to cover for items of cost which are not known exactly at the time the estimate is developed. This could be because of incomplete engineering, lack of time to get definitive pricing, minor errors and omissions and minor changes, within the scope. The Association for the Advancement of Cost Engineering (AACE) defines contingency as, 'An amount added to the estimate to (1) achieve a specific confidence level, or (2) allow for changes that experience shows will likely be required.' [5]. Contingency is described in many different ways across the industry, but the common purpose for determining contingency is to account for the uncertainty or unexpected.

MOTI Project Cost Estimating Guidelines [6] indicate that cost estimates should always include contingency to cover for certain uncertainties and risks. Contingency is an item in a cost estimate like any other. It should be presented as a separate line to have it clearly identified. It is not 'padding' and it is expected to be spent during the life of the project. By no means, should it be considered as a reserve fund to compensate for inaccurate estimating, changes of scope or 'nice-to-haves'. In addition, it should not provide for costs associated with external influences (i.e. those not under the control of the project manager or estimator), such as strikes or work stoppages; changes in government policies and regulations; natural disasters, major accidents, catastrophes or significantly abnormal weather; management reserves; and escalation and currency effects.

Last, but not least, the amount of contingency required should be determined very carefully. Remember a cost estimate, which does not contain enough contingency may jeopardize the success of the project and could lead to cost overruns. Equally as important, placing too much contingency in a cost estimate could impact in a negative way the project 'go/no-go' decision. It should also be noted that too much contingency represents money which cannot be used on other projects.

\section{METHODS FOR ESTIMATING THE COST CONTINGENCY}

There are numerous methods used to estimate the required contingency. At the simplest level, there is the percentage approach, where the contingency is calculated as an across-the-board percentage addition to the base estimate. Baccarini [7] indicates that this is the most common approach for estimating project cost contingency. However, this method is overly simplistic 
and fails to explicitly acknowledge the underlying project risks that drive the need for contingency in the first place and therefore exposes the organization to either overcompensating for risk or underestimating risk.

A slightly better method consists of calculating a contingency percentage for each major cost element, which at least acknowledges that some parts of the project may have greater uncertainty than others. According to Mak et al. [8], this is still insufficient, because a single-figure prediction of estimated costs implies a degree of certainty that is not justified.

The weaknesses of the traditional percentage addition approach for calculating contingencies had led for a search for more robust approaches. Baccarini [9] conducted a literature review of these methods. Monte Carlo simulation was found to be the most widely accepted method for estimating the required cost contingency as project cost estimators become more aware of its improved effectiveness over the traditional percentage approach. The Project Management Body of Knowledge (PMBOK) [10] advocates its use for performing quantitative risk analysis.

\section{DATA COLLECTION}

A fictitious case study, based on a typical capital transportation construction project, was developed to provide a structured way to estimate the contingency value using Monte Carlo simulation. The first step for estimating the required cost contingency consists of dividing the project into manageable cost elements. Depending on the type of project, generic Cost Estimating Structures (CES) or Work breakdown structures (WBS), which consist of the major categories of work that make up the project, could be used.

The vast majority of capital transportation construction projects entail the same fundamental cost elements (see Table 1). MOTI Appendix 1 - Cost elements for Transportation Projects [6], provides a detailed description of each of these cost elements and the methods used to estimate them, depending on the maturity of the project. Note that the estimation figures used to derive the total project cost of $\$ 280 \mathrm{M}$ (base estimate) are arbitrary and do not represent real costs.

Once the cost elements of the project are well defined, the next step consists of determining for each cost element, the Most Likely Cost, High Cost and Low Cost to represent the uncertainty that each cost element presents. According to MOTI [6], during early stages of a project, the amount of uncertainty can be quite high (30\% to 40\%). As the project progresses, the uncertainty decreases (5\% to $10 \%)$.

It is recommended to use the AACE Cost Estimate Classification system [11] to determine how the costs are distributed between the Low Cost and the High Cost and what methodology

Table 1: Total project cost estimate in thousand dollars.

\begin{tabular}{lcll}
\hline Cost element & Most Likely cost & Low cost & High cost \\
\hline Project management & $\$ 14,000$ & $\$ 12,600$ & $\$ 16,800$ \\
Planning & $\$ 4,200$ & $\$ 3,780$ & $\$ 5,040$ \\
Design & $\$ 28,000$ & $\$ 25,200$ & $\$ 33,600$ \\
Property acquisition & $\$ 84,000$ & $\$ 75,600$ & $\$ 100,800$ \\
Environmental & $\$ 9,800$ & $\$ 8,820$ & $\$ 11,760$ \\
Construction & $\$ 140,000$ & $\$ 126,000$ & $\$ 168,000$ \\
Total project cost & $\$ \mathbf{2 8 0 , 0 0 0}$ & & \\
\hline
\end{tabular}


to use to estimate the Most Likely cost, depending on the maturity of the project. Our case study was based on Class 3 estimate, which corresponds to a pre-tender cost estimate awaiting budget authorization. The uncertainty of each cost element can then be examined using probability distributions. For illustration purposes and to keep things simple, the triangular distribution was used to represent the Low Cost, Most Likely Cost and High Cost, since its shape can be described by three-point estimates.

Finally, data on correlation between the cost elements should also be collected, since correlation has an impact on the contingency value. Historical data and expert judgement can be used to determine how cost elements are correlated between each other.

\section{RUNNING THE MONTE CARLO SIMULATION}

Once the data collection process is complete, the Monte Carlo simulation can be executed to determine the overall risk for the combined costs of the project. We used the @ Risk and Decision Tools software from the Palisade Corporation, as the number of iterations required makes this process impossible to do by hand.

For each iteration, the Monte Carlo simulation randomly selects a cost for each item, in accordance with the specified probability distribution, and then adds together the costs of all elements, to get the total project cost. The procedure is repeated many times. When the simulation is completed, the total project costs generated from each iteration are plotted on a histogram. The distribution of costs for the total project forms the basis for estimating the cost contingency required.

\section{RESULTS}

Figure 1 and 2 show the simulation results, based on 10,000 iterations. Typically, 5,000 iterations and more are used for most project risk analyses. Three important results can be noted:

- First, the most likely cost for the project, represented by the mean, was estimated to be approximately \$289.33 M.

- Second, the base estimate, as shown in Figure 2, is about $20 \%$ likely to be $\$ 280 \mathrm{M}$ or less and $80 \%$ likely to be overrun.

- Third, the total project cost at the 90th percentile is approximately: $\$ 303.46 \mathrm{M}$.

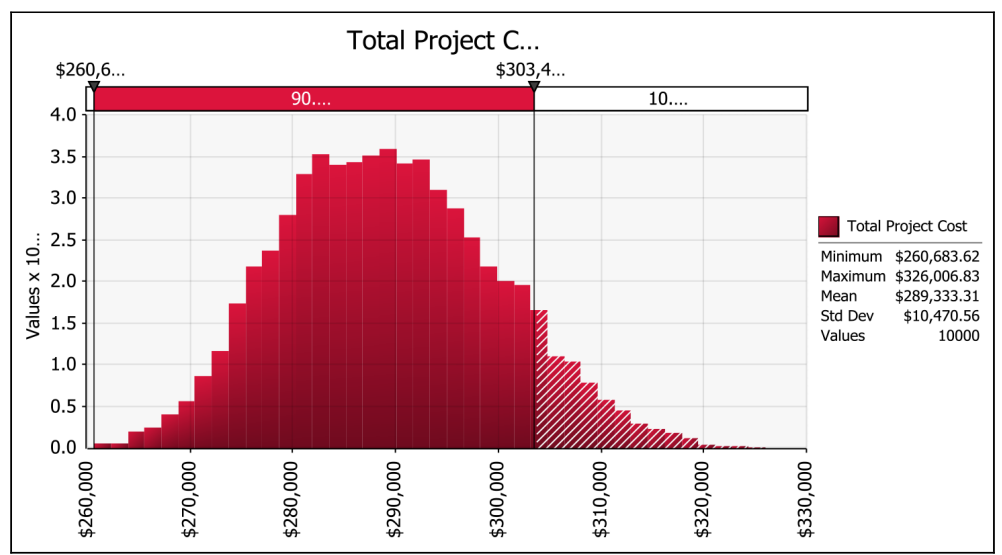

Figure 1: Probability distribution graph for the total project cost. 
So, how much contingency is required on the project to guarantee that the total project cost is not to be exceeded at a certain confidence level? To answer this question, Let us assume that the Ministry of Transportation and Infrastructure is very conservative and will not accept to bid a project that has a likelihood of overrunning that is greater than $10 \%$. Since the contingency is 'An amount added to the estimate to achieve a specific confidence level', this means that the difference between the base estimate and the total project cost at the 90th percentile is the amount of contingency that would be necessary to provide the company with the assurance that the estimated total project cost will not exceed the level of acceptable risk of $10 \%$. Therefore, the required amount of contingency for the current case study at the $90 \%$ confidence level is $\$ 23.46 \mathrm{M}(\$ 303.46 \mathrm{M}-\$ 280 \mathrm{M})$. In terms of percentage, this represents a contingency of $8.4 \%$. This result is consistent with what the literature says about the percentage of contingency required for a typical pre-tender estimate (5\% to $10 \%)$. Note that a higher confidence level (95\% and above), the amount of contingency required would be slightly greater.

\section{SENSITIVITY ANALYSIS}

In order to reduce the amount of contingency, a sensitivity analysis can be conducted to detect the key cost elements affecting the total project cost. The bars in Fig. 3 show the cost elements which contribute the most risk to the total project. The length of the bars is the amount of change in the output due to a +1 standard deviation change in the input. As shown in Fig. 3, Construction and Property Acquisition proved to be the most contributing factor to the risk of the total project cost. Particular efforts should then be directed towards these cost elements, in order to reduce the impact of risk events and uncertainties to the total project cost, as well as the amount of contingency required.

\section{CORRELATION ANALYSIS}

Correlation between cost elements also has an impact on the contingency value. To demonstrate the potential effects of correlation, an analysis of a hypothetical case was conducted assuming that each cost element is positively correlated with Construction and the correlation factor is 0.8 .

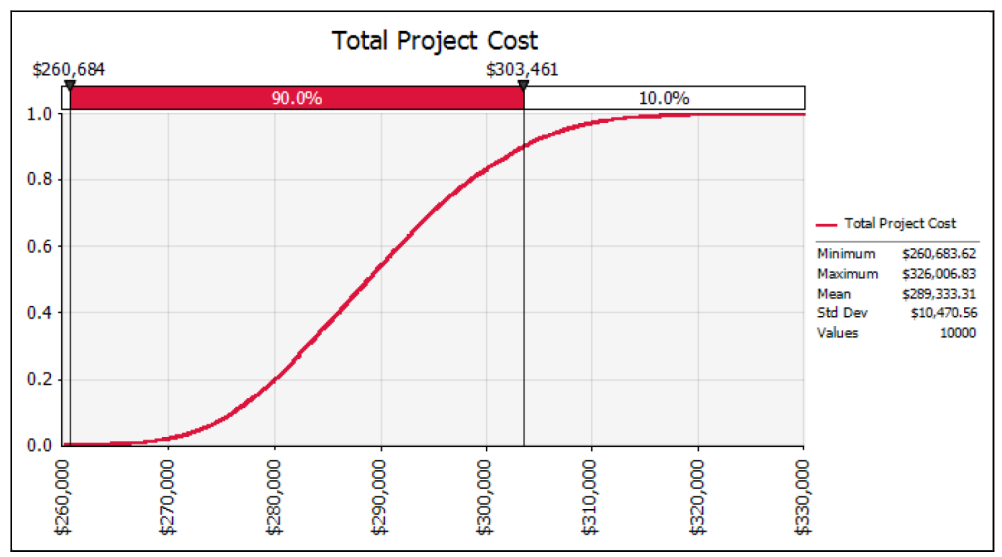

Figure 2: Cumulative distribution chart for the total project cost. 


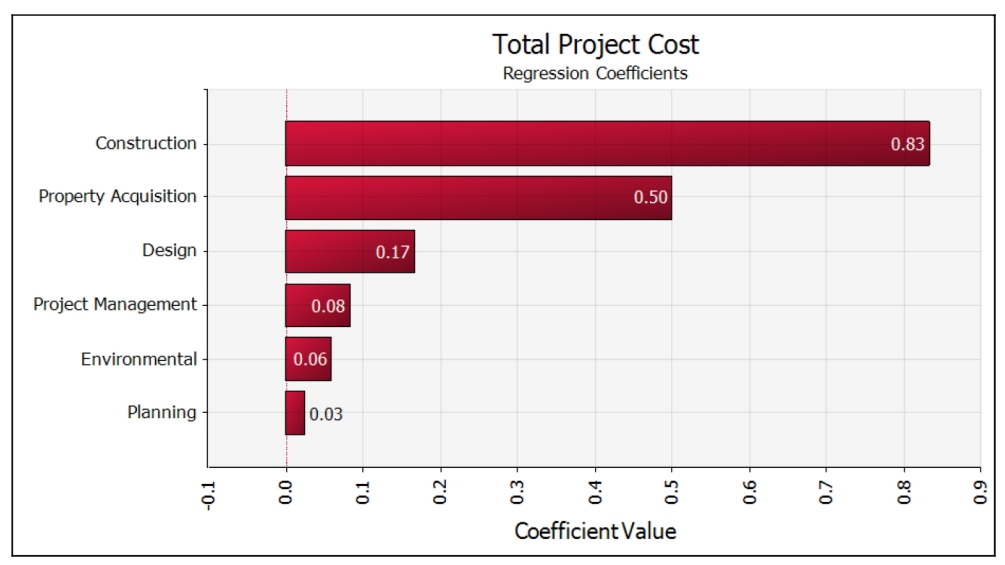

Figure 3: Bar chart showing the contribution of the cost elements to the risk in the project.

Table 2: Comparison of statistics for the total project cost without correlation and with correlation.

\begin{tabular}{lcc}
\hline Statistics & No Correlation & Correlation \\
\hline Minimum & $\$ 260684$ & $\$ 256875$ \\
Maximum & $\$ 326007$ & $\$ 329126$ \\
Mean & $\$ 289333$ & $\$ 289333$ \\
Mode & $\$ 289263$ & $\$ 281371$ \\
Median & $\$ 288817$ & $\$ 288295$ \\
Std Dev & $\$ 10471$ & $\$ 13213$ \\
\hline
\end{tabular}

Tables 2 and 3 below display the simulation results without and with correlation. By comparing the statistics of both scenarios, one can see that the mean is the same but the standard deviation and the range width (measures of dispersion) have increased in the case of the scenario with correlation. Comparing the percentiles shows that the contingency value needs to be slightly greater at higher levels of confidence when a positive correlation exists between the project cost elements, based on the assumptions. As highlighted in the table, the presence of a positive correlation between the project cost elements, as specified, would slightly raise the risk of cost overruns at the 60th percentile level and higher.

\section{CONCLUSION}

Based on a fictitious case study, this paper demonstrated how the Monte Carlo simulation can assist project managers in estimating the contingency value to be allocated to their project, to mitigate the risk of project cost overruns. The proposed methodology provided answers to the following questions: (1) What is the most likely cost? (2) How likely is the baseline cost estimate to be overrun? (3) How much contingency is required for the project to guarantee that the total project cost is not to be exceeded at a certain confidence level? This involved dividing the project into manageable cost elements and carefully collecting data on low, most likely and high possible costs, as well as on correlation between the cost elements. The @ 
Table 3: Comparison of statistics for the total project cost without correlation and with correlation.

\begin{tabular}{lcc}
\hline Percentile $(\%)$ & No correlation & Correlation \\
\hline 1 & $\$ 267680$ & $\$ 263201$ \\
5 & $\$ 273151$ & $\$ 268836$ \\
10 & $\$ 276077$ & $\$ 272647$ \\
15 & $\$ 278248$ & $\$ 275245$ \\
20 & $\$ 280095$ & $\$ 277604$ \\
25 & $\$ 281662$ & $\$ 279666$ \\
30 & $\$ 283076$ & $\$ 281503$ \\
35 & $\$ 284503$ & $\$ 283258$ \\
40 & $\$ 286040$ & $\$ 284897$ \\
45 & $\$ 287400$ & $\$ 286540$ \\
50 & $\$ 288817$ & $\$ 288295$ \\
55 & $\$ 290289$ & $\$ 290241$ \\
60 & $\$ 291729$ & $\$ 292085$ \\
65 & $\$ 293185$ & $\$ 294073$ \\
70 & $\$ 294719$ & $\$ 296238$ \\
75 & $\$ 296459$ & $\$ 298537$ \\
80 & $\$ 298470$ & $\$ 301148$ \\
85 & $\$ 300814$ & $\$ 303917$ \\
90 & $\$ 303461$ & $\$ 307692$ \\
95 & $\$ 307238$ & $\$ 420385$ \\
99 & & \\
\hline
\end{tabular}

Risk tool from the Palisade Corporation was used to provide the power of the Monte Carlo simulation. This paper also showed the importance of cost risk analysis to identify the major key cost elements that contribute the most risk to the total project cost and where efforts should be focused, in order to prevent cost overruns. It has also demonstrated how correlation between cost elements could also affect the contingency value, thus providing a complete and sound cost estimating and analysis approach that contribute to fostering and bolstering the credibility of risk analysis results.

\section{REFERENCES}

[1] Auger, M., Procurement organizations: a global comparison, economics, resources and international affairs division - parliamentary information and research service, publication N0. 2014-82-E, Ottawa, Canada, pp. 4-10, 2014.

[2] Flyvbjerg, B., What you should know about megaprojects and why: an overview. Project Management Journal, 45(2), pp. 6-19, 2014. http://dx.doi.org/10.1002/pmj.21409 
[3] Younossi, O., Arena, M.V., Leonard, R.S., Roll, C.R., Jain, A. \& Sollinger, J.M., Is Weapon System Cost Growth Increasing? A Quantitative Assessment of Completed and Ongoing Programs, RAND: California, US, pp. 44-46, 2007.

[4] Flyvbjerg, B., Holm, M.S. \& Buhl, S., Underestimating costs in public works projects: error or lie? Journal of the American Planning Association, 68(3), pp. 279-295, 2002. http://dx.doi.org/10.1080/01944360208976273

[5] AACE (American Association of Cost Engineers), AACE International's risk management dictionary. Cost Engineering, 42(4), pp. 28-31, 2000.

[6] Ministry of Transportation and Infrastructure (MOTI), Project cost estimating guidelines, Version 01.02, Victoria BC, pp. 8-10, 2013.

[7] Baccarini, D., Understanding project cost contingency - a survey, Cobra International Construction Conference, Brisbane, 2005.

[8] Mak, S., Wong, J. \& Picken, D., The effect on contingency allowances of using risk analysis in capital cost estimating: a Hong Kong case study. Construction Management and Economics, 16, pp. 615-619, 1998. http://dx.doi.org/10.1080/014461998371917

[9] Baccarini, D., Estimating project cost contingency - beyond the 10\% syndrome. Australian Institute of Project Management Conference, Victoria: Australian Institute of Project Management, 2005.

[10] Project Management Institute, A Guide to the Project Management Body of Knowledge (PMBok), 4th edn., Project Management Institute: USA, 2008.

[11] ACCE International, Cost estimate classification system - as applied in engineering, procurement, and construction for the process industries, Recommended Practice No. 18R-97, TCM Framework: 7.3 - Cost Estimating and Budgeting, 2011. 